EGU2020-161

https://doi.org/10.5194/egusphere-egu2020-161

EGU General Assembly 2020

(c) Author(s) 2020. This work is distributed under

the Creative Commons Attribution 4.0 License.

\title{
Investigate human responses to Late-Holocene changes of fluvial landforms through Spatial Point Pattern Analysis (Po Plain, N Italy)
}

\author{
Filippo Brandolini ${ }^{1}$ and Francesco Carrer $^{2}$ \\ ${ }^{1}$ Dipartimento di Scienze della Terra "Ardito Desio", Università degli Studi di Milano, Milano, Italy \\ (filippo.brandolini@unimi.it) \\ ${ }^{2}$ McCord Centre for Landscape, Newcastle University, UK (francesco.carrer@newcastle.ac.uk)
}

In fluvial environments, alluvial geomorphological features had a huge influence on settlement strategies during the Holocene. However, a few projects investigate this topic through quantitative and question-driven analyses of the human-landscape correlation. The Po Valley ( $\mathrm{N}$ Italy) - located between the Mediterranean regions and continental Europe - is as a key area for the investigation of environmental and cultural influences on settlement strategies since prehistoric times. For instance, the transition from Roman to Medieval times represented a crucial moment for the reorganisation of human settlement strategies in the Po Valley; the process was mainly driven by climate changes and socio-political factors. Spatial Point Pattern Analysis (SPPA) was here employed to provide a solid statistical assessment of these dynamics in the two historical phases. A point pattern (PP) corresponds to the location of spatial events generated by a stochastic process within a bounded region. The density of the PP is proportional to the intensity of the underlying process. The intensity, in turn, can be constant within the region or spatially variable, thus influencing the uniformity of distribution of spatial events. SPPA provides powerful techniques for the statistical analysis of PP data that consist of a complete set of locations of archaeological sites/findings within an observation window. The use of spatial covariates enables the investigation of environmental and non-environmental factors influencing the spatial homogeneity of the point process. Archaeologists have increasingly analyzed such datasets to quantify the characteristics of observed spatial patterns with the aims of deriving hypotheses on the underlying processes or testing hypotheses derived from archaeological theory. The aim of this paper is to assess whether a shift in water management strategies between the Roman and Medieval periods influenced the spatial distribution of settlements, and to evaluate the relative importance of agricultural suitability over flood risks in each historical phase. In particular, the variability settlement patterns between Roman and Medieval phases has been assessed against two related proxies for alluvial geomorphology and agricultural suitability: flood hazard and soil texture. The SPPA performed shows that Roman and Medieval settlement patterns mirror two different human responses to the geomorphological dynamics of the area. Roman land- and watermanagement were able to minimize the flood hazard, to drain the floodplain and organize a complex land use on different soil types. In the Medieval period, the alluvial geomorphology of the area, characterised by wide swampy meadows and frequent flood events, affected the spatial organisation of settlement, which privileged topographically prominent positions. Social and 
cultural dynamics played a crucial role in responding to alluvial geomorphological environmental challenges in different times. 